\title{
Compre o SEU FUtURo! O CENÁRIo ATUAL DA MERCANTILIZAÇÁO DA EDUCAÇÁO PROFISSIONAL NO BRASIL
}

\author{
BuY YOUR FUTURE! THE CURRENT SCENARIO OF THE \\ MERCANTILIZATION OF PROFESSIONAL EDUCATION IN BRAZIL
}

\begin{abstract}
Francisco das Chagas Silva Souza
Doutor em Educação. Docente do IFRN, Campus Mossoró. Docente do Programa de Pós-Graduação em Educação Profissional (IFRN), do Programa de Pós-Graduação em Educação Profissional e Tecnológica (ProfEPT) e do Programa de Pós-Graduação em Ensino (UERN/IFRN/UFERSA). ORCID: https://orcid.org/0000-0002-9721-9812 chagas.souza@ifrn.edu.br
\end{abstract}

Verônica Dantas de Araújo Albano Mestranda do Programa de Pós-Graduação em Ensino (UERN/IFRN/UFERSA). ORCID: https://orcid.org/0000-0001-8600-6419 veronik_uern@hotmail.com

\begin{abstract}
Resumo: Neste artigo, objetivamos discutir a ampliação da Educação Profissional em instituiçóes privadas de ensino. A metodologia constou de pesquisas nos sites de seis empresas que ofertam cursos de formação profissional com a finalidade de compreender como se apresenta o discurso da empregabilidade, da qualificação e da competência como estratégia de marketing para atrair 'alunos-clientes'. Baseados em revisão de literatura acerca do tema privatizaçáo da educação profissional no Brasil, consideramos que a ampliação do setor privado na educação brasileira decorre do aprofundamento da política neoliberal, que reduz a participação do Estado nos investimentos e dissemina a ideia da inserção no mercado mediante a aquisição de cursos de capacitação, geralmente curtos, fornecidos pelas instituiçóes de ensino, sobretudo privadas, muitas das quais com a obtenção de financiamentos públicos.
\end{abstract}

Palavras-Chave: Empregabilidade; Neoliberalismo; Privatização; Qualificação.

AbstraCt: In this article, we aim to discuss the expansion of Professional Education in private teaching institutions. The methodology consisted of researches on the websites of six companies that offer professional training courses in order to understand how they presented the discourse of employability, qualification and competence as a marketing strategy to attract student-clients. Based on a review of the literature on the topic privatization of professional education in Brazil, we consider that the expansion of the private sector in Brazilian education stems from the deepening of neoliberal policies in recent decades. They have reduced the state's participation in investments and disseminated the idea of market insertion through acquisition of training courses, 
generally short-term courses, provided by educational institutions, especially private ones, many of them are financed by public funds.

KeYwords: Employability; Neoliberalism; Privatization; Qualification.

\section{Introduçáo}

A expansão do mercado da educação, nas últimas décadas, é uma realidade que náo pode ser negada, como nos mostram estudos realizados por Ball (2014) e Shiroma (2015), dentre tantos outros pesquisadores de reconhecida importância no campo da educação. No Brasil, com a promessa de um futuro digno para milhares de pessoas que estão excluídas de um mercado de trabalho cada vez mais exigente e em transformaçáo, empresas oferecem cursos técnicos e de qualificação profissional, além de cursos superiores e de pós-graduação lato e stricto sensu.

No que diz respeito aos cursos de Educação Profissional (em níveis técnico, tecnológico e de qualificação), eles têm se expandido nos últimos anos, principalmente na rede privada (muitas vezes, com subsídios públicos), com base no discurso que relaciona a capacitação profissional à inserção, quase imediata, no mercado de trabalho. Portanto, mediante o chamado das empresas, o mercado da educação atrai mais clientes, ou seja, alunos, e, por sua vez, recebe o retorno esperado: lucros.

Neste artigo, discutimos a ampliação da Educação Profissional como um ramo de negócios de empresas privadas. Associamos o crescimento e as ações dessas instituiçôes mercantis de educação ao contexto socioeconômico e político das últimas décadas, marcado pelo aprofundamento do ideário neoliberal e da globalização. (GENTILI, 1996; CHARLOT, 2007; BALL, 2014; SHIROMA, 2015)

Para o alcance desse objetivo, realizamos pesquisa nos sites de empresas que oferecem tais cursos com o intuito de conhecer a estratégia de marketing utilizada por elas na sua busca por conquistar alunos-clientes. Feita essa verificação, selecionamos seis empresas que atuam em âmbito nacional e regional. A rede social Facebook também foi fonte de recolha de dados, visto que nela as empresas divulgam folders, imagens, comentários e frases de motivação. Nos sites das empresas e na opção 'imagem' do Google buscamos conhecer os apelos visuais usados pelos empresários da educa- 
ção. Concomitante a essa pesquisa na Internet, realizamos uma revisão de literatura acerca do tema privatização da educação no Brasil, com ênfase na Educação Profissional.

Este artigo está dividido em duas seçóes: na primeira, descrevemos os resultados da nossa pesquisa na Internet; em seguida, discutimos a ampliação da privatização da educação no Brasil, com foco na Educação Profissional, considerando a sua relação com o estágio atual do capitalismo, o padrão de acumulação flexível.

\section{O futuro no balcão de negócios}

Conforme observamos nas estatísticas do Anuário Brasileiro da Educação Básica $2017^{1}$, na última década houve um crescimento acelerado da Educação Profissional privada no Brasil. Segundo essa fonte, em 2015 havia 3.423 instituiçóes privadas ofertando essa modalidade de ensino, um número que supera a soma dos estabelecimentos de todas as dependências públicas federais (574), estaduais (2.591) e municipais (163), ou seja, 3.328. Caso comparemos esse quantitativo com o dos estabelecimentos federais, veremos que esse número é 596\% maior.

Podemos afirmar que a diferença nas ofertas entre as redes públicas e privadas de Educação Profissional se dá em função de fatores de ordem econômica e política, associados ao apelo mercadológico de empresas que oferecem cursos técnicos, geralmente de curta duração, apresentados como a única alternativa que o indivíduo tem de se inserir num mercado de trabalho promissor, mas extremamente seletivo.

O crescimento das matrículas na rede privada de Educação Profissional nos estimulou a procurar, na Internet, algumas empresas que atuam nessa área em níveis nacional e regional. Em seguida, selecionadas seis delas para a realização de uma pesquisa exploratória nos seus sites e na rede social Facebook, haja vista que as empresas escolhidas usam o espaço virtual para divulgar informaçóes por meio de uma linguagem mais acessível para o público que desejam atrair, sobretudo jovens interessados em se capacitar na tentativa de conseguir uma vaga no mercado de trabalho. $\mathrm{Na}$ Internet, coletamos os folders utilizados pelas empresas para a venda dos cursos. Detivemo-nos nos seguintes termos para filtrar os resultados, sen- 
do pesquisados um por vez: campanha cursos técnicos, educação profissional, empresas de educação profissional, empresa, cursos técnicos.

As visitas aos sites das empresas justificam-se pela importância que eles têm para manter a divulgação do negócio tendo em vista a luta pela sobrevivência num mercado cada dia mais competitivo. Seguindo a concepção de que a propaganda é a alma do negócio, elas comercializam seus cursos mostrando porque são 'melhores' que suas concorrentes e procurando, assim, garantir uma imagem de empresa moderna e dotada de novas tecnologias. Dessa maneira, reproduz-se hoje o que as "universidades mercantis" (CALDERÓN, 2000) fizeram nos anos 1990:

[...] a década de 90 apresentou uma guerra pelo consumidor, na qual, longe de mostrar compromisso com a excelência acadêmica, as universidades utilizaram-se de estratégias de sedução do cliente em potencial: os jovens egressos do segundo grau. Assim, criaram-se grandes campanhas veiculadas pelos principais meios de comunicação, com artistas de TV, modelos jovens dentro de um mundo de ilusáo, mostrando que estudar em uma universidade não é uma coisa chata, pelo contrário, é prazerosa e divertida, como estar em um clube de férias. (SAMPAIO, 1998 apud CALDERÓN, 2000, p. 65-66)

$\mathrm{Na}$ organização dos sites das empresas pesquisadas, observamos inicialmente a página principal (Home) contendo os folders dos cursos, valores das matrículas, mensalidades e formas de pagamento. $\mathrm{O}$ item denominado 'institucional' traz o histórico, a missão e os locais de atuação da empresa. $\mathrm{Na}$ sequência, há a apresentação da infraestrutura, a partir de textos e fotos das instalações físicas. A opção 'Conheça nossos cursos' apresenta os cursos, a carga horária, a duração, os dias letivos, o perfil profissional que se espera do aluno egresso. Porém, nem todas as empresas divulgam as matrizes curriculares dos cursos que ofertam.

O item 'Fale conosco', usado por quatro empresas, é um espaço para os clientes tirarem dúvidas, darem sugestôes ou fazerem reclamaçôes. As notícias apresentadas nos sites geralmente estão relacionadas à empresa, mantendo-a sempre como uma referência para a sociedade quando a questão é qualificação profissional. 
Duas das seis empresas pesquisadas apresentam um sistema acadêmico integrado nos seus sites. Nele, há o portal do professor, onde é feito o lançamento das aulas e das avaliaçóes; e o portal do aluno, no qual os discentes consultam a sua situação acadêmica. Nos sites, os clientes (alunos) fazem a pré-matrícula, sem sair de casa, efetivando-a, depois, presencialmente. A taxa a pagar, na maioria das vezes, é oferecida em caráter promocional ou com o valor parcelado, conforme simulação disponibilizada nos sites. Como o cliente precisa do produto, a saber, do curso, e as empresas necessitam vendê-lo, estas negociam para que os valores possam ser pagos de acordo com a realidade financeira do aluno. Outras vezes oferecem promoçôes de 'pacotes' de cursos, como nas redes de supermercado. Duas empresas utilizam o item 'Depoimentos' para a postagem de mensagens de alunos ou egressos que relatam a importância da instituiçáo para as suas vidas no tocante à realização profissional.

$\mathrm{Na}$ disputa pelo cliente, os sites e o Facebook das empresas estão carregados de um marketing visual. É evidente a preocupação de três empresas pesquisadas em exibir as instalaçóes físicas das escolas por meio de fotografias e textos curtos e descritivos. As imagens geralmente apresentam os materiais didáticos e os laboratórios em que são desenvolvidas as aulas práticas dos cursos. Muitas vezes também são expostas fotografias do estacionamento, da recepção e da sala de estudos. O importante é que não restem dúvidas para o cliente quanto ao investimento que está prestes a fazer.

Os sites das seis empresas pesquisadas também expóem o perfil dos egressos dos cursos e as suas áreas de atuação. O objetivo é prestar todos os esclarecimentos acerca do profissional qualificado que o interessado será, sem que ele necessite se deslocar para a escola a fim de receber informaçóes, o que faz a empresa ganhar tempo para a concretização da venda do curso.

$\mathrm{Na}$ batalha pela conquista do cliente, a empresa $\mathrm{A}^{2}$ utiliza frases motivadoras como: "Conquiste seu lugar no mercado de trabalho"; "Tenha a oportunidade de se qualificar"; "Aproveite nossos descontos"; "Aqui seu futuro é garantido"; "O mercado quer técnicos, você está preparado?"; "Diga sim para os seus sonhos"; "Nós temos a direção certa para você"; "Acerte o alvo, venha para a nossa escola"; "Matricule-se no curso X e ganhe gratuitamente o curso Y"; "Você pensa o futuro a nossa escola realiza com você" ou "Quem estuda aqui tem futuro garantido". 
A empresa B garante ao aluno-cliente que: "A educação é o caminho mais rápido para conseguir o primeiro emprego"; "A vida traça caminhos com a empresa "B"; "Você segue rumo às suas conquistas"; "A importância do curso técnico no mercado de trabalho"; "Inscreva-se sem precisar fazer prova"; "Quem faz empresa B faz a diferença" e "A qualidade de ensino e conforto que você merece". A instituição também apresenta dados e fotos de ex-alunos que conquistaram espaço no mercado, reforçando a ideia de que, para obter um emprego, basta se qualificar.

A empresa "C", como as demais, usa frases apelativas, tais como "Procurando sua tão sonhada vaga de emprego?"; "Seja um profissional completo e conquiste o mercado de trabalho"; "A melhor estrutura com o menor preço"; "Não perca esta oportunidade"; "Conquiste o mercado e a sua independência financeira"; "Todos os cursos reconhecidos"; "Você tem pouco tempo para estudar? Faça como os alunos da turma X"; "Venha fazer parte deste grupo"; "O caminho para o seu sonho está aqui, não perca essa oportunidade"; "Corre que ainda dá tempo" e "Saiba que o mercado procura os profissionais que nós formamos!" Além disso, utiliza imagens de alunos em aula, sorrindo e expressando satisfação, e fotos ilustrativas de profissionais já atuando na área dos cursos ofertados pela escola. O discurso implícito é o de que quem ingressa nesses cursos tem a oportunidade de ser igual a um daqueles trabalhadores felizes por estarem empregados no mercado.

$\mathrm{Na}$ busca pela conquista de novos alunos, a empresa D destaca as seguintes frases: "Cursos rápidos de atualização: aqui, você encontra o curso que precisa e aprende de forma rápida e eficaz"; "Aqui o seu esforço ganha força"; "Vagas abertas"; "A gente acredita em você"; "Amplie sua área de atuação, conheça os cursos que podem te ajudar"; "As oportunidades se multiplicam para quem tem um segundo idioma"; "Dê um salto no seu crescimento profissional"; "Invista em sua carreira e conquiste novas oportunidades"; "O Leandro se dedicou aos estudos e conseguiu um novo emprego. Agora é a sua vez"; "Seu futuro depende do hoje, não do amanhâ". A empresa evidencia os cursos rápidos como um atalho para conquistar a capacitação desejada em menos tempo e, consequentemente, a empregabilidade. Para comprovar esses resultados, ainda enfatiza a história de um aluno que foi bem-sucedido no processo de capacitação e, posteriormente, obteve sua realização profissional. 
Já a empresa E enfatiza: "Inicie seu sonho com R \$ 49,00 e até 50\% da bolsa"; "Seja o seu melhor e conquiste um diploma valorizado no país inteiro"; "Cabe no seu bolso"; "Bem-vindo à melhor fase da sua carreira"; "O jeito mais rápido de melhorar o seu currículo".

Uma sexta empresa, a F, interage com o público a partir das seguintes frases: "Educação com qualidade para ajudar você a criar e construir conhecimentos"; "Invista em sua carreira"; "Mensalidade congelada até o final do curso"; "Pense inteligente. Pense empresa F"; "Últimas vagas, inscreva-se já”. Assim como a empresa anterior, esta apoia-se nas vantagens financeiras, um atrativo para qualquer cliente.

As ilustraçôes no Google, na opção 'imagem' e nos sites das empresas, mostram pessoas felizes no trabalho, tendo em mãos instrumentos do ofício tais como: pastas, bolsas, computadores, cadernos e carteiras de trabalho, variando conforme a profissão apresentada nas imagens. Quanto aos alunos, eles aparecem nas mais diversas situaçóes de aprendizagem no âmbito dos seus cursos, em volta das mesas, demonstrando afinidade com os futuros materiais de trabalho e com o professor (ou instrutor), também representado como alguém feliz na realização do seu trabalho. O intuito é associar qualificação, realização profissional e felicidade tanto durante a realização do curso quanto no seu término.

\section{Privatização da educação no Brasil: 'novos' velhos interesses no mercado da educação}

Para Rodrigues (2002, p. 102-103), “toda relação hegemônica é necessariamente uma relação pedagógica, que demanda aparelhos de hegemonia, isto é, instrumentos que organizam e difundem as ideias dominantes". Adiante, afirma que a educação "[...] está sendo agora conclamada a atender às novas demandas do padrão de acumulação flexível.” (op.cit., p. 111).

É certamente por isso que, no Brasil, é comum a mídia anunciar que existem vagas de emprego e que essas não são ocupadas por falta de qualificaçáo do trabalhador. Os títulos de algumas matérias da imprensa e de sites de empresas deixam explícita a falta de competência técnica do trabalhador: "Sobra falta de qualificação profissional no mercado de trabalho" 
(LOBATO, 2012), "De um lado, desemprego; de outro, vagas sobrando em empresas" (JORNAL NACIONAL, 2016), "Mercado de trabalho: há vagas, mas faltam profissionais - Por quê?” (BRÁZ, 2014)

Os sites que visitamos, como também as imagens que verificamos no Google, revelam os interesses do capital em 'estimular' o trabalhador a prosseguir na busca de aprender o necessário para aprimorar o desempenho da sua função. É como se o seu desemprego ou o seu baixo salário fossem causados pela sua incapacidade, despreparo e desatualização. Logo, os futuros clientes das instituiçóes privadas de ensino passam literalmente a comprar cursos na obsessão de vencer na vida. O engodo logo é descoberto, pois a flexibilização que caracteriza o capitalismo contemporâneo, "expressa na diminuição drástica das fronteiras entre atividade laboral e espaço da vida privada, no desmonte da legislação trabalhista, nas diferentes formas de contratação da força de trabalho e em sua expressão negada, o desemprego estrutural" (ANTUNES; PRAUN, 2015, p. 412), não dará a segurança a esse trabalhador que se esforçou para se qualificar. Assim, o risco de perder o emprego, a individualizaçáo no espaço de trabalho, a necessidade de cumprir metas, o assédio moral, dentre outros fatores, geram uma variedade de doenças do trabalho e, até mesmo, suicídios, como analisam esses autores.

De acordo com Oliveira (2003, p. 19), os conceitos de competência, empregabilidade e flexibilidade nascem da tentativa de adequar a educação aos imperativos da nova ordem econômica, marcada pela globalização e pela racionalidade neoliberal, a qual "apregoa, cada vez mais, a necessidade de a escola subordinar-se às demandas do setor produtivo". Dessa forma, "a escola passa a se responsabilizar pela formação de uma mão-de-obra adequada às modificaçóes no mundo do trabalho." Para o autor em tela, os termos competência, empregabilidade e flexibilidade "representam estratégias das elites, visando retirar da materialidade das relaçóes capitalistas a responsabilidade pela exclusão social e pelo desemprego." (op.cit., p. 32) Propaga-se a concepção de que as chances de se obter um emprego serấo ampliadas a partir do momento em que as pessoas dispuserem de um capital cultural maior ou de uma melhor qualificação. Todavia, tal discurso mascara a realidade da economia brasileira, que náo garante a geração de novos postos de trabalho, como assinala o referido pesquisador: 
Existe uma incapacidade de a economia gerar novos postos de trabalho. Não adianta se propagar que a maior qualificação, a desregulamentação das leis trabalhistas ou que o entendimento entre trabalhadores e empresários produzirá o surgimento de mais empregos. É de fato necessário que o governo assuma sua responsabilidade nesse processo, intervindo no setor, criando, inclusive, uma nova legislação trabalhista se for necessário. Mas isto tem que ocorrer em simultaneidade com a mudança de sua postura em relaçáo à política de desenvolvimento. Faz-se necessário que o governo opte por um desenvolvimento econômico direcionado para os interesses dos setores excluídos. (op.cit., p. 34)

Nessa direção, para Oliveira (2003, p. 36), o conceito de empregabilidade surge como "um mecanismo que retira do capital e do Estado a responsabilidade pela implementação de medidas capazes de garantir um mínimo de condiçôes de sobrevivência para a população.”

Da mesma forma, Pino (2001) também dá conta da precarizaçáo do trabalho na fase atual do capitalismo. Para ele, é ingênuo acreditar que é possível corrigir as distorções do mercado de trabalho pela qualificação dos trabalhadores, pois isso gera maior número de pessoas qualificadas e, por conseguinte, maior competitividade, de modo que, em dado momento, devido à competição, as pessoas aceitarão qualquer emprego por qualquer salário.

Obviamente, essa realidade não é revelada. Ao contrário, é obscurecida pelo marketing que as empresas de educação empregam, como vimos nas frases apelativas e nas imagens dos sites pesquisados, induzindo os trabalhadores a procurar outra capacitação, colocando-se como responsáveis por sua escolaridade, haja vista o Estado se isentar desse dever. Nesse aspecto, destaca Gentili (1996, p. 27 - grifos no original):

O Estado neoliberal é mínimo quando deve financiar a escola pública e máximo quando define de forma centralizada o conhecimento oficial que deve circular pelos estabelecimentos educacionais, quando estabelece mecanismos verticalizados e antidemocráticos de avaliação do sistema e quando retira autonomia pedagógica às instituiçóes e aos atores coletivos da es- 
cola, entre eles, principalmente, aos professores. Centralização e descentralização são as duas faces de uma mesma moeda: a dinâmica autoritária que caracteriza as reformas educacionais implementadas pelos governos neoliberais.

Para Gentili o conhecimento se torna uma mercadoria que será consumida pelo aluno, agora um cliente ávido para concorrer a uma vaga no mercado de trabalho. Para esse autor, em outra obra, a expansão dos cursos no setor privado é resultado do imediatismo pela qualificação, semelhante à oferta de refeições nos fast foods. Assim como os McDonald's, as instituiçóes escolares tornam-se empresas produtoras de serviços rápidos: "[...] o que unifica os McDonald's e a utopia educacional dos homens de negócios é que, em ambos, a mercadoria oferecida deve ser produzida de forma rápida e de acordo com certas e rigorosas normas de controle da eficiência e da produtividade." (op.cit., p. 29) Daí a oferta de tantos cursos técnicos e superiores de curta duração, com horários flexíveis para atender às necessidades dos alunos-clientes ou a distância, ou em fins de semana, como podemos encontrar nos sites das empresas que pesquisamos.

No marco da reestruturação neoliberal, a função da escola passa a ser formar e selecionar para o emprego, o que não pode ocorrer sem um controle do currículo e das práticas pedagógicas. Como observa Stephen Ball (2014), professor do Instituto de Educação da Universidade de Londres, o neoliberalismo transforma as relaçóes sociais em calculabilidades e intercâmbios, isto é, na forma de mercado e, portanto, na mercantilização da prática educacional. Para esse pesquisador, "As tecnologias neoliberais trabalham em nós para produzir um corpo docente e discente 'dócil e produtivo', e professores e alunos responsáveis e empreendedores." (2014, p. 64) Com base nisso, Ball (op.cit., p. 66) constrói o conceito de performatividade, a

forma por excelência de governabilidade neoliberal, que abrange a subjetividade, as práticas institucionais, a economia e o governo [...] A performatividade convida-nos e incita-nos a tornar-nos mais efetivos, a trabalharmos em relação a nós mesmos, a melhorarmos a nós mesmos e a sentirmo-nos culpados ou inadequados se não o fizermos. Ela opera dentro de um ar- 
cabouço de julgamento no qual a definição de "aperfeiçoamento" e de eficácia é determinada por nós e indicada por medidas de qualidade e de produtividade. A performatividade é aplicada por meio de medidas e metas contra as quais se espera que nos posicionemos, mas, muitas vezes, de maneiras que produzem incertezas quanto à forma de como deveríamos nos organizar em nosso trabalho. [...] A performatividade "funciona" mais poderosamente quando está dentro de nossas cabeças e de nossas almas. Ou seja, quando nós aplicamos em nós mesmos, quando assumimos a responsabilidade de trabalhar duro, mais rápido e melhor, assim "melhoramos" nossa "produção" como parte de nossa autovalorização e valorização dos outros.

Em outro texto, Ball (2013, p. 461) informa que a performatividade compóe a tríade das tecnologias políticas utilizadas no Reino Unido, desde o governo Thatcher ${ }^{3}$, e "consiste no desenvolvimento de medidas, de indicadores baseados em 'sinais de mercado', mas que funcionam também como meio de o Estado controlar e definir metas para o gerenciamento e monitoramento do setor público."

A mcdonaldização da escola, destacada por Gentili (1996), e a performatividade, salientada por Ball $(2013,2014)$, a nosso ver, agem num mesmo sentido: formar trabalhadores segundo as demandas do mercado. Entretanto, essa formação precisa ser rápida e eficiente em termos de tempo e quantidade. O espírito competitivo extrapola as empresas e se incorpora no trabalhador, que precisa sentir-se eficaz e qualificado para exercer a sua tarefa e manter-se no emprego. Com esse fim, as instituiçóes de ensino profissionalizante passam a desenvolver uma pedagogia alicerçada na instrumentalização do aluno, para que este desenvolva, com competência, tarefas que, geralmente, estão desvinculadas de aprofundamento teórico. Como ressalta Kuenzer (2000, p. 86), essa polivalência, que não pode ser confundida com politecnia, amplia a capacidade do trabalhador "para aplicar novas tecnologias, sem que haja mudança qualitativa desta capacidade.” Logo, ele é levado a desempenhar diferentes tarefas usando conhecimentos distintos, porém, sem superar o caráter de parcialidade e fragmentação dessas práticas ou compreender a totalidade. Nessa direção, 
"É suficiente usar os conhecimentos empíricos disponíveis sem apropriarse da ciência, que permanece como algo exterior e estranho." (id.ib.)

Para propiciar a escolarização apenas produtiva do trabalhador, esse modelo de educaçáo dissocia do processo elementos que provocam a formação de indivíduos atuantes politicamente na sociedade em que estáo inseridos, uma vez que isso é visto como desnecessário para quem deverá apenas cumprir tarefas. Dessa maneira, reproduz-se o dualismo histórico na educação: "[...] a divisão capitalista faz com que a atividade intelectual e material, o gozo e o trabalho, a produção e o consumo caibam a indivíduos distintos, tanto as relaçóes sociais e produtivas como a escola, educam o trabalhador para esta divisão.” (KUENZER, 2002, p.79) Por conseguinte, os trabalhadores são empurrados "para os cursos de qualificação profissional, majoritariamente sob controle do capital privado, para o qual a educação torna-se o novo e mais lucrativo 'nicho de mercado'." (BATISTA, 2013, p. 208) A educação passa a ser um campo "fértil” para se investir, principalmente se for de acordo com os princípios neoliberais que apontam para a privatização como sinal de qualidade.

Com base nesse pressuposto, conforme Oliveira e Almeida (2009), tornou-se comum pensar que o investimento na formaçáo do trabalhador deve ser responsabilidade dele próprio, desvirtuando a educação como direito social para sua condição de dever individual. Em função do marketing divulgado a favor das vendas dos cursos de qualificação da mão de obra, o capital firma compromisso com a garantia do emprego, uma promessa que conquista aqueles que acreditam no retorno imediato do seu 'investimento'. Na tentativa disfarçada de promover a universalização da educação, o empresariado, na verdade, objetiva suprir as suas próprias necessidades, valendo-se de um discurso hegemônico.

Para Charlot (2007), as implicações da globalização e do neoliberalismo nas políticas de educação são muitas e estão ligadas às mudanças sofridas pelo mercado em função de novas lógicas trazidas por esses processos: as lógicas da qualidade, da eficácia e da diversificação, e o correspondente que elas impóem ao Estado. Dessa forma, "o Estado Regulador substitui o Estado desenvolvimentista. Essa mudança do Estado não pode deixar de incidir sobre a escola, seja ela pública ou particular." (CHARLOT, 2007, p. 131) Com base nesse argumento, o autor exemplifica açóes, no campo da educação, realizadas pelo Estado em conjunto com empresas privadas 
dos Estados Unidos. É assim que o Estado se torna um cliente, como observa Shiroma (2015) ao analisar o fornecimento privado de serviços públicos sob a forma de parcerias público-privadas construídas pelo governo britânico para realizar inspeção de escolas.

No caso brasileiro, o mesmo autor chama a atenção, dentre outras coisas, para a propagação de cursos de língua inglesa, em detrimento de outros idiomas, e o ingresso de grandes multinacionais nas escolas: "Coca-Cola, por exemplo, paga para a escola disponibilizar uma máquina distribuindo Coca-Cola. Nestlé envia material gratuito sobre o que é uma boa alimentação e Colgate interessa-se pela higiene dentária." (CHARLOT, 2007, p. 133). Também nessa direção, Oliveira (2009, p. 740) identifica quatro consequências da globalização para a educação, todas elas eivadas de tensôes e contradiçôes:

a) a crescente centralidade da educação na discussão acerca do desenvolvimento e da preparação para o trabalho, decorrente das mudanças em curso na base técnica e no processo produtivo; b) a crescente introduçáo de tecnologias no processo educativo, por meio de softwares educativos e pelo recurso à educação a distância; c) a implementação de reformas educativas muito similares entre si na grande maioria dos países do mundo; d) a transformação da educação em objeto do interesse do grande capital, ocasionando uma crescente comercialização do setor.

Com relação à última consequência, esse autor destaca as palavras de Angel Gurria, Secretário-geral da Organização para a Cooperação e Desenvolvimento Econômico (OCDE), em manifestaçáo realizada em Lagonissi, Grécia, em junho de 2006, ao encerrar a conferência de Ministros de Educação daquela Organização: "A educação é hoje uma mercadoria negociável. Tornou-se exportável, portável e negociável.” (OLIVEIRA, 2009, p. 740) Com relaçáo ao Brasil, o autor relata a expansão das universidades privadas, que se fundem com outras, nacionais e estrangeiras, para melhor controlar o mercado da educação:

[...] mais do que sua transformação em mercadoria, o que estamos observando, no caso do ensino superior, é um processo 
intenso de concentração. Assim, é possível falarmos, também, em processo de oligopolização. Ou seja, o número de fornecedores tende a se concentrar ainda mais nos próximos anos e uma fatia significativa do mercado tende a ficar com os maiores grupos. Mantidas as condiçôes atuais de sustentação exclusivamente por mensalidades, poucos serão os que conseguirão ocupar nichos específicos do mercado sem ser acossados pelas instituições maiores. (op.cit., p. 754)

Importa destacar que o avanço do setor privado na educação brasileira não é algo recente. Calderón, em 2000, já destacava o crescimento do que ele denominou "universidades mercantis", nas últimas décadas do século XX. Haddad e Gracindo (2003, p. 69) ressaltaram que "entre o final da década de 90 até 2002, a cada semana foram abertas, em média, três instituiçóes particulares de ensino superior no Brasil, a maioria de pequeno porte." Certamente, essas instituiçôes de pequeno porte de que tratavam os autores, há mais de uma década, foram posteriormente fundidas com as maiores ou destruídas pela concorrência.

Ao abordar a privatização da educação nos últimos anos, André Inácio Lula da Silva, "a retórica neoliberal, pelo menos oficialmente, perdeu força, e entrou em cena o chamado neodesenvolvimentismo, que postula que o Estado deve adotar medidas de política econômica para conjugar crescimento e distribuição de renda." Entretanto, destaca que, conforme Castelo (apud ANTUNES, 2013, p. 15), não houve um rompimento do governo Lula com o neoliberalismo, pois esse governo "continua fazendo privatizaçóes, agora sob o modelo de concessóes e PPPs [parcerias público-privadas], mantém a meta inflacionária, e quando tem algum problema nas contas externas aumenta os juros", logo, "Há mudanças pontuais, mas o essencial da política ainda é neoliberal." A discussão é polêmica, caso consideremos os ganhos sociais que tivemos neste início de século. Todavia, a parceria público-privada, na educação brasileira, principalmente na oferta de cursos superiores, é um fato que não pode passar despercebido, embora náo seja algo novo, como nos mostra Davies (2004) ao fazer uma retrospectiva sobre a proteção dada pelo Estado à educação privada ao longo do século XX. 
No tocante às ofertas de cursos de Educação Profissional, em níveis técnicos ou de capacitação de curta duração, essas parcerias têm se intensificado. De acordo com Melo e Moura (2016, p. 111), o Programa Nacional de Acesso ao Ensino Técnico e Emprego (Pronatec) serviu para que o governo brasileiro transferisse vultosos recursos públicos à iniciativa privada, dinamizando o mercado específico da Educação Profissional em detrimento da educação pública: "As transferências de 2011 a 2014 somam quase 6,5 bilhôes de reais. Desse montante, 1,8 bilhóes destinaram-se à esfera pública e 4,7 bilhóes à privada, ou seja, 73\% dos recursos do Pronatec são repassados ao capital privado, e apenas $27 \%$ à esfera pública." A expansão da Educação Profissional privada, por meio do Pronatec, também é destacada por Guimarães (2014, p. 16):

No cômputo geral, a maioria dos cursos realizados no âmbito do Pronatec são de responsabilidade do Sistema S - 70\% do total [...]. Aqui, as instituiçôes de ensino superior aparecem com apenas $2 \%$ do total de matrículas. Mas o Sistema $S$ tem destaque principalmente nos cursos de formação inicial e continuada, que têm no mínimo 160 horas e geram muito mais matrículas no mesmo intervalo de tempo. Nessa modalidade, só o Senai e o Senac, juntos, são responsáveis por $86 \%$ de todas as matrículas realizadas até hoje. Já as instituiçōes privadas de ensino superior estão avançando sobre os cursos técnicos que, embora sejam minoritários no Pronatec - correspondem a apenas 30\% do total das matrículas -, têm sido o foco principal da rede pública federal.

O autor ainda destaca que a 'oportunidade' dada pelo setor público para o privado é comemorada por este último, na opinião de um diretor da Anhanguera-Kroton, a maior empresa educacional do mundo: "Todos ganham nessa relação: o país, os alunos, que passam a ter mais opçóes de formação qualificada, a indústria e mercado em geral e, também, as instituições de ensino participantes do programa." Conforme Guimarães (2014), essa empresa tinha, em 2014, 35 mil alunos em cursos técnicos, por meio do Pronatec, e anunciou a abertura de mais 28 mil vagas no segundo semestre daquele ano, totalmente financiadas pelo Governo Federal. O 
grupo Estácio, que vem logo abaixo no ranking brasileiro de instituições de ensino superior, tinha, em 2014, quase 25 mil matrículas no Rio de Janeiro. Em um Comunicado ao Mercado feito em julho daquele ano, o grupo anunciou a "autorização para ofertar aproximadamente mais $15 \mathrm{mil}$ vagas, das quais mais de 7 mil nas regióes Norte e Nordeste.” (op. cit., s/p) A transferência de recursos públicos para essas instituiçóes privadas de ensino superior também é apresentada por Guimarães (2014, p. 17), que esclarece que, em maio de 2014, " $63,2 \%$ dos alunos da Kroton e 46,9\% dos da Anhanguera na modalidade presencial estudam via Fies. [...] só pelo Fies, a Anhanguera Educacional Ltda. recebeu, em 2013, mais de R\$ 536 milhões de recursos públicos.”

Portanto, embora Ball $(2013 ; 2014)$ tenha realizado as suas pesquisas no Reino Unido, ao que tudo indica estamos assistindo, também no Brasil, a fase que ele denomina de pós-neoliberal do relacionamento do Estado com o setor privado. Para ele, não se trata de um neoliberalismo livre e selvagem, em que o mercado é autorizado a seguir o seu curso em qualquer setor na busca de obter maiores lucros. Ao contrário, “o Estado se transformou num 'criador de mercados', num regulador e monitor das ações do setor privado [...] produzindo relaçôes de mercado

\section{Consideraçóes finais}

O avanço da globalização e o fortalecimento do ideário neoliberal têm trazido transformaçóes profundas no setor produtivo e, em decorrência deste, no mercado de trabalho. A rapidez com que essas mudanças impactam a sociedade contemporânea náo deixa de fora as Instituiçôes de Ensino Superior e as que ofertam cursos de Educação Profissional, que 
logo se aproximam dos pressupostos neoliberais e enfatizam a eficiência, a qualidade e a concorrência.

Nesse cenário, as instituições privadas de educação (mas não apenas elas) apresentam-se como a única opção que o trabalhador tem para se qualificar profissionalmente e conseguir uma inserção em um mercado de trabalho cada vez mais seletivo, exigente e excludente. Por assim o ser, essas instituiçóes passam a desenvolver a pedagogia das competências, cujo projeto educacional está pautado, conforme Araújo e Rodrigues (2011), na capacidade efetiva, em oposição à ideia de capacidade potencial, nas capacidades profissionais em movimento e não mais fixas em postos de trabalho, nas capacidades humanas amplas, antes desvalorizadas e desestimuladas nos ambientes produtivos.

Portanto, tomando como exemplo as empresas pesquisadas, verifica-se que elas se esforçam na massificação do discurso da urgência do mercado por profissionais qualificados e, por isso, as pessoas não podem perder tempo e devem, o quanto antes, adquirir um curso que lhes oportunizem um emprego, talvez até o primeiro de sua vida. Como qualquer outro consumidor, o aluno-cliente selecionará a empresa que tiver melhores instalaçôes e/ou preços (muitas vezes chamados de 'investimentos') que caibam no seu orçamento.

Por fim, recorrendo, mais uma vez, às consideraçôes de Ball (2013, p. 462), "Os sujeitos neoliberais são empreendedores, criativos, solipsistas, individualistas e desenvolvem um tipo de subjetividade que o neoliberalismo necessita para sobreviver. [Assim] é necessário compreender tais desdobramentos como um conjunto de mudanças econômicas concretas, mas também como um conjunto de mudanças no interior das subjetividades", afinal, o neoliberalismo não está apenas lá fora, na economia, mas também aqui dentro, em nossas cabeças.

Diante desse cenário, resta aos educadores problematizar as suas ações cotidianas nos espaços educativos e construir uma educação focada no ser humano emancipado em contraposição àquela centrada na formação do cidadão produtivo, voltada para a lógica do mercado que distorce, manipula e cria novos conceitos a seu bel prazer (FRIGOTTO; CIAVATTA, 2003). Urge que ouçam o alerta de Paro (1999) e se oponham, de maneira contra hegemônica, à formação de trabalhadores para o atendimento precípuo dos interesses do capital. 


\section{Notas}

1 Os dados do Anuário Brasileiro da Educação Básica 2017 foram elaborados com base nas estatísticas do Instituto Nacional de Estudos e Pesquisas Educacionais Anísio Teixeira (INEP). Para esse órgão, a Educação Profissional de Nível Médio engloba as categorias Normal/Magistério, concomitante ao Ensino Médio, subsequente ao Ensino Médio, integrada ao Ensino Médio e integrada à EJA de Nível Médio.

2 Para que não fiquem expostos os nomes das empresas, preferimos denominá-las seguindo uma sequência alfabética: $A, B, C, D, E$ e $F$.

3 De acordo com Ball (2013, p. 461 - grifos no original), as outras duas tecnologias políticas săo: "a 'forma de mercado', criando oportunidades para a 'escolha' e para a 'competiçấo', seja no interior dos serviços públicos já estabelecidos ou introduzindo a concorrência de fornecedores privados de serviços públicos. Ao lado disso, vemos também a introdução de formas de gestáo que, por meio do fortalecimento do poder de controle dos gestores, fazem as instituições funcionarem de modo eficaz e eficiente de acordo com o modelo das organizaçóes empresariais, isto é, de maneira a incentivar o engajamento de todos nesse processo de competição."

\section{Referências}

ANTUNES, A. Anos 2000: continuidade ou ruptura do desmonte neoliberal? Revista POLI - Saúde, Educação e Trabalho, Rio de Janeiro, v. 6, n. 31, nov./dez. 2013, p. 14-19.

ANTUNES, R.; PRAUN, L. A sociedade dos adoecimentos no trabalho. Serviço Social \& Sociedade, São Paulo, n. 123, jul./set. 2015, p. 407-427.

ANUÁRIO BRASILEIRO DA EDUCAÇÃO BÁSICA 2017. São Paulo: Moderna, 2017.

ARAÚJO, R. M. L.; RODRIGUES, D. S. Referências sobre práticas formativas em Educação Profissional: o velho travestido de novo ante o efetivamente novo. In: ARAÚJO, R. M. L.; RODRIGUES, D. S. (Orgs). Filosofia da práxis e a didática na Educação Profissional. Campinas: Autores Associados, 2011. p. 7-43.

BALL, S. J. Privatizaçóes da educação e novas subjetividades: contornos e desdobramentos das políticas (pós)neoliberais. Entrevista concedida a Sanny Silva da Rosa. Revista Brasileira de Educação, Rio de Janeiro, v. 18, n. 53, abr./jun. 2013, p. 457-466.

BALL, S. J. Educação Global S.A.: novas redes políticas e o imaginário neoliberal. Ponta Grossa: UEPG, 2014.

BATISTA, E. L. Educação Profissional no Brasil: análise do projeto industrial burguês para a formação de trabalhadores nos primórdios do século XX. In: BATISTA, E. L.; MUller, M. T. (Orgs.). A Educação Profissional no Brasil. Campinas: Alínea, 2013. p. 155-180. 
BRÁZ, A. S. Mercado de trabalho: há vagas, mas faltam profissionais - Por quê?. Jornal do Brasil, 12 out. 2014. Disponível em: http://www.jb.com.br/sociedade-aberta/ noticias/2014/10/12/mercado-de-trabalho-ha-vagas-mas-faltam-profissionais-por-que/ Acesso em: 8 jun. 2017.

CALDERÓN, A. I. Universidades mercantis: a institucionalização do mercado universitário em questão. São Paulo em perspectiva, São Paulo, v. 14, n. 1, jan./mar., 2000, p. 61-72.

CHARLOT, B. Educação e globalização: uma tentativa de colocar ordem no debate. Sisifo, Lisboa, n. 4, out./nov. 2007, p. 129-136.

DAVIES, N. O financiamento da educação e seus desafios. ECCOS - Revista Científica Uninove, São Paulo, v. 6, n. 1, 2004, p. 43-63.

FRIGOTTO, G.; CIAVATTA, M. Educar o trabalhador cidadão produtivo ou o ser humano emancipado? Trabalho, Educação e Saúde, Rio de Janeiro, v. 1, n. 1, jan./ago. 2003, p. 45-60.

GENTILI, P. Neoliberalismo e educação: manual do usuário. In: SILVA, T. T.; GENTILI, P. (Orgs.). Escola $S$. A.: quem ganha e quem perda no mercado educacional do neoliberalismo. Brasília, DF: CNTE (Confederação Nacional dos Trabalhadores em Educação), 1996. p. 9-49.

. Três teses sobre a relação trabalho e educação em tempos liberais. In:

SANFELICE, José Luís; SAVIANI, Dermeval; LOMBARDI, José Claudinei. (Orgs.). Capitalismo, trabalho e educação. Campinas: Autores Associados, Histedbr, 2002. p. 45-59.

GUIMARÃES, C. Anhanguera-Kroton: capital financeiro avança sobre a educação. Revista POLI - Saúde, Educação e Trabalho, Rio de Janeiro, v. 6, n. 35, jul./ago. 2014, p. 16-18.

HADDAD, S.; GRACIANO, M. Educação: direito universal ou mercado em expansão. São Paulo em perspectiva, São Paulo, v. 18, n. 3, jul./set. 2004, p. 67-77.

JORNAL NACIONAL. De um lado, desemprego; de outro, vagas sobrando em empresas. Globo, Rio de Janeiro, 11 jul. 2016. Disponível em: http://g1.globo.com/ jornal-nacional/noticia/2016/07/de-um-lado-desemprego-de-outras-vagas-sobrandoem-empresas.html Acesso em: 8 jun. 2017.

KUENZER, A. Z. Ensino médio: construindo uma proposta para os que vivem do trabalho. São Paulo: Cortez, 2000.

KUENZER, A. Z. Exclusão includente e inclusão excludente: a nova forma de dualidade estrutural que objetiva as novas relaçóes entre educação e trabalho. In: LOMBARDI, J. C.; SAVIANI, D.; SANFELICE, J. L. (Orgs.). Capitalismo, trabalho e educação. Campinas, São Paulo: Autores Associados, Histedbr, 2002. p. 77-95. 
LOBATO, P. H. Sobra falta de qualificação profissional no mercado de trabalho. Em.com.br, 26 out. 2012. Disponível em: https://www.em.com.br/app/noticia/ economia/2012/10/26/internas_economia,325693/sobra-falta-de-qualificacaoprofissional-no-mercado-de-trabalho.shtml Acesso em: 8 jun. 2017.

MELO, T. G. S.; MOURA, D. H. Programa Nacional de Acesso ao Ensino Técnico e Emprego (Pronatec): expansão e privatização da Educação Profissional. Holos, Natal, v. 6, 2016, p. 103-119.

OLIVEIRA, R. A (des)qualificação da educação profissional brasileira. São Paulo: Cortez, 2003.

OLIVEIRA, R. P. A transformação da educação em mercadoria no Brasil. Educação \& Sociedade, Campinas, v. 30, n. 108, out. 2009, p. 739-760.

OLIVEIRA, S. A. Z. P.; ALMEIDA, M. L. P. Educação para o mercado x educaçáo para o mundo do trabalho: impasses e contradiçóes. Revista Espaço Pedagógico. Passo Fundo, v. 16, n. 2, jul/dez. 2009, p. 155-167.

PARO, V. H. Parem de preparar para o trabalho!!! Reflexóes acerca dos efeitos do neoliberalismo sobre a gestão e o papel da escola básica. In: FERRETTI, C. J. et al. (Orgs). Trabalho, formação e currículo: para onde vai a escola. São Paulo: Xamã, 1999. p. 101-120. Disponível em: https://social.stoa.usp.br/articles/0016/3148/ Vitor_Paro_Parem_de_preparar_para_o_trabalho.pdf Acesso em: 18 jun. 2018.

PINO, M. D. Política educacional, emprego e exclusão social. In: FRIGOTTO, G; GENTILI, P. (Orgs.). A cidadania negada: políticas de exclusão na educação e no trabalho. São Paulo: Cortez, 2001. p. 65-87.

RODRIGUES, J. A educação e os empresários: o horizonte pedagógico do capital. In: FRIGOTTO, G.; CIAVATTA, M. (Orgs.). A experiência do trabalho e a educação básica. Rio de Janeiro: DP\&A, 2002. p. 101-113.

SHIROMA, E. O. O estado como cliente: interesses empresariais na coprodução da inspeção escolar. Trabalho Necessário, Niterói, v. 13, n. 22, 2015, p. 57-79.

Recebido em 24 jun. 2018 / Aprovado em II out. 2019 Para referenciar este texto:

SOUZA, F. C. S.; ALBANO, V. D. A. Compre o seu futuro! O cenário atual da mercantilização da educação profissional no Brasil. EccoS - Revista Científica, São Paulo, n. 51, e8835, out./dez. 2019. Disponível em: https://doi.org/10.5585/EccoS. n5I.8835. 